\title{
The influence of pulsed redox conditions on soil phosphorus
}

\author{
R. Scalenghe ${ }^{1,2}$, A. C. Edwards ${ }^{3}$, E. Barberis ${ }^{4}$, and F. Ajmone Marsan ${ }^{4}$ \\ ${ }^{1}$ SAGA, Università di Palermo, Palermo, Italy \\ ${ }^{2}$ HydrASA, CNRS/Université de Poitiers, UMR6269, Poitiers, France \\ ${ }^{3}$ Macaulay Institute, Aberdeen, UK \\ ${ }^{4}$ DIVAPRA, Università di Torino, Grugliasco, Italy
}

Received: 17 November 2010 - Accepted: 7 December 2010 - Published: 13 December 2010

Correspondence to: R. Scalenghe (scalenghe@unipa.it)

Published by Copernicus Publications on behalf of the European Geosciences Union.

\begin{abstract}
The effects of eleven pulsed reduction-oxidation cycles (20 and 2 days, respectively) on soil phosphorus $(P)$ dynamics are compared for 12 soils having contrasting properties and overfertilised with respect to P. Incubation conditions simulated transient waterlog5 ging of the soil profile and involved repeated sampling and analysis of both the solution and solid phase $\mathrm{P}$ forms. An initial increase in $\mathrm{P}$ concentration occurred upto and including the fourth full cycle was followed by a sharp decline in concentration for all but one soil. Accompanying changes in the main extractable forms of $P$, which appeared to be cumulative, could be summarised as a general decline in the organic $P$ fraction

10 and an overall increase in amorphous associated inorganic forms of P. The fact that up to $60 \%$ of the total soil $P$ was demonstrated to change its sensitivity for a particular extractant suggests that these operationally defined $\mathrm{P}$ forms can experience substantial transformations. There was also a suggestion that certain changes in P forms may not be reversible. While the laboratory conditions represent an extreme situation changes

15 in timing and frequency of intense precipitation events, as predicted in many climate change scenarios, may increase the risk of episodic soil waterlogging. The potential onset of reducing conditions even for periods of less than twenty days will influence soil $\mathrm{P}$ dynamics and short-term bioavailable $\mathrm{P}$. Various mechanisms are involved but the robustness of sequential extraction procedures and general soil test methods (e.g.

20 Olsen) for quantifying and reliably distinguishing specific soil $\mathrm{P}$ forms/associations are questioned.
\end{abstract}

\section{Introduction}

The phosphorus cycle and its interaction with other environmental compartments has been the subject of considerable recent research particularly in view of its role in eutrophication of water bodies (e.g. Reddy et al., 2005). 
The onset of anoxic conditions within soil can alter $\mathrm{P}$ equilibria through the solubilisation of redox sensitive mineral constituents $(\mathrm{Mn}$ and $\mathrm{Fe})$ and the simultaneous release of associated (adsorbed or co-precipitated) $\mathrm{P}$ anions. The shift in redox equilibria towards a more reductive system could also involve a release of $P$ from the organic

5 fraction, which acts as an electron donor, and a possible dissolution of $\mathrm{P}$-carbonates as a result of the shift in $\mathrm{pH}$ in calcareous soils.

Actual rates and extent of reduction will depend on various soil properties, local environmental factors (e.g. temperature; Suplee and Cotner, 2002), biological activity and availability of reducible compounds (e.g. nitrate, metal oxides). The spatial scale

10 over which reducing conditions actually develop may vary from the centre of individual soil aggregates to isolated topographic hollows within fields or whole river flood plains (Williams, 1959; Rinklebe et al., 2007; Grunth et al., 2008) or coastal environments (Zhang et al., 2010).

The most comprehensive understanding of the role of reduction (e.g. James and

15 Bartlett, 2000) has been obtained in relation to periodic flooding of paddy soils for rice production (Ponnamperuma, 1972). In dry cultivation and natural environments poor drainage and seasonally raised water-tables may result in the temporary saturation of soils with the development of reducing conditions. Despite the investment in artificial under-drainage of agricultural land many soils still experience periodic anoxia due

20 to soil compaction as a consequence of excessive trafficking, irrigation, and management practices (Niedermeier and Robinson, 2007). Riparian buffer strips are especially prone to flooding (Pant et al., 2002).

At a global scale, a greater tendency for heavy summer storms resulting in localised flooding conditions have been predicted as one possible consequence of climate change (Christensen et al., 2007; Meehl et al., 2007). While considerable uncertainty and geographical differences in future climate change scenarios is likely, a general prediction is for an increased incidence of extreme precipitation events and this would in turn lead to more frequent inundation of soils (Banach et al., 2009).

9011

The work of researchers has mostly focussed on the effects of long submersion periods. Less emphasis has been given to understanding the likely significance that shortterm reducing conditions, such as those that could develop during episodic precipitation events, might have on soil processes. A range of processes operate during wetting 5 and drying cycles, which influence microbial community structure and activity (Gordon et al., 2008; Grunth et al., 2008; Unger et al., 2009; Wegener and Boetius, 2009) together with precipitation/solubilisation of minerals (Phillips, 1998). While changes in the availability of $P$ and arsenic (As), that resemble in many respects as both occur in the same group of the periodic table, have been studied for individual soils (e.g.

10 Ascar et al., 2008; Gao et al., 2008; Hernandez and Meurer, 2000; Mukherjee et al., 2009; Phillips and Greenway, 1998; Schärer et al., 2009) a comparison involving soils of widely different properties would be useful.

In a previous paper (Scalenghe et al., 2002) we described the effects that an extended period (600 days) of continuously reducing conditions had upon the solubility and chemical forms of $P$ in a diverse group of overfertilised soils from the European Union. In this study the same 12 soils were used to investigate the effect of repeated short-term saturation and drying cycles on soil $\mathrm{P}$ forms. Changes in the solution concentrations and solid phase $P$ forms together with some general environmental consequences of the loss of $P$ are discussed.

\section{Materials and methods}

\subsection{Soils}

Two thirds of the 32 World Reference Base Groups (IUSS WG WRB, 2006) (i.e. three quarters of the twelve Soil Taxonomy Orders, Soil Survey Staff, 2010) are represented in significant amounts in Europe. The twelve soils chosen are taxonomically repre25 sentative of roughly half these and range from Regosols (Entisols), to Vertisols (Vertisols) typically dominating the Mediterranean environments, to Chernozems (Alfisols and Mollisols) of the cooler mid-latitudes. 
When considered together the twelve pedoenvironments vary widely in geographical position (from parallel $38^{\circ}$ to $57^{\circ} \mathrm{N}$ and from meridian $6^{\circ} \mathrm{W}$ to $11^{\circ} \mathrm{E}$ ), climate (mean annual air temperature ranges from 7.5 to $18.5^{\circ} \mathrm{C}$ and mean annual rainfall from 490 to $900 \mathrm{~mm}$ ) and pedoclimate (moisture regimes is xeric for the southernmost soils and 5 udic for the other soils, temperature regimes vary from frigid to thermic).

Half of the European Union, two million square kilometres by landmass, is farmed and a wide range of land use exists, although there has been a general intensification, often associated with excessive addition of nutrients. Nutrient surpluses occur when accumulated inputs are greater than losses and are common in conventional agricul-

10 ture, especially livestock systems. The selected soils are "overfertilised" as defined by having at least twice the optimum concentration of available $P$ as estimated using the official analytical methods of its relevant country. All the soils are intensively farmed and crops range from horticulture to fruit production, from mixed/arable systems to rice (paddy).

15 All sampled Ap horizons were sieved to $<2 \mathrm{~mm}$ and stored in an air-dry condition. The soils and their relevant general properties are described in Barberis et al. (1996) while the redox relevant information can be found in Scalenghe et al. (2002). The sampled soils can be grouped into (1) calcareous, C, (E1, E2 and I3), (2) slightly acid, SA, (D1, D2, E3 and I2), (3) acid and rich in organic matter, AOMR, (G3, G6 and G9), 20 and (4) acid and light-textured, ALT, (D3 and I1) (Delgado and Torrent, 1997). The latter group contains two soils with extreme properties: D3 is a sandy soil with a large amount of extractable $\mathrm{P}$ and $\mathrm{I1}$ was sampled from a rice growing region, and therefore will have experienced periodic flooding as a routine agronomic practice.

\subsection{Pulsed reducing conditions - experimental design}

25 Individual cycles consisted of a short duration water-saturation phase (20 days) followed by oxic conditions ( 1 day) and drying (1 day). Three grams of soil and $15 \mathrm{~mL}$ of $0.01 \mathrm{M} \mathrm{CaCl}_{2}$ were measured into $20 \mathrm{~mL}$ vials (pre-purged with $\mathrm{N}_{2}$ ) sealed and incubated in an anaerobic box. A gas mixture of $p \mathrm{~N}_{2}=0.88 ; p \mathrm{CO}_{2}=0.08 ; p \mathrm{H}_{2}=0.04$ 9013

was chosen to best mimic the components most likely present under naturally anoxic conditions. Hydrogen was flushed through a Pd catalyser to remove the residual $\mathrm{O}_{2}$.

All vials were subjected to a reduction period of 20 days $(298 \mathrm{~K})$ followed by a $24 \mathrm{~h}$ pulse of oxidized conditions when the vials were flushed with $\mathrm{O}_{2}$ and exposed to open 5 air at $313 \mathrm{~K}$; the samples were then freeze-dried for $24 \mathrm{~h}$ before the cycle was repeated. Vials were shaken daily for 20 min during the 20 day reducing stage.

Freeze-drying is preferable to air-drying (Zhou et al., 2008) which alters much more both the pore network and the soil phenotypic profile (Deacon et al., 2008). For this reason some initial testing of the likely effects of the freeze-drying method was under10 taken prior to designing the main experiment. Four of the experimental soils (D3, E3, $\mathrm{G} 3, \mathrm{I1})$ contrasting in their individual properties were tested in a pre-experiment. A series of non-reduced (oxic) soil samples was contrasted against ones that had experienced a reduction period. The differences that were observed in $\mathrm{P}$ forms after reduction were not apparent for the non-reduced samples. Changes in composition

15 under non-reduced conditions were negligible and fell well within the standard error obtained for the soils that experienced reduction. This would suggest that the P transformations described below are primarily due conditions induced during the reduction phase.

The entire cycle was repeated 11 times. A 20 day saturation period was chosen

20 as this was known from previous studied to approximate full reduction for this range of soils under these experimental conditions (Scalenghe et al., 2002). The short oxidation period was selected because, unlike the reduction process, responses to oxidation are generally rapid and no significant changes in $P$ solubility are observed afterwards. At the end of each reduction period the sealed vials were centrifuged at $1800 \mathrm{~g}$ then $5 \mathrm{~mL}$

25 of the supernatant were sampled using a syringe and acidified to $\mathrm{pH}<3$ in order to minimise precipitation.

Centrifuging was preferred to filtering as it ensured the maintenance of reducing conditions. The solutions were analyzed for $\mathrm{P}, \mathrm{Mn}$ and Fe. At the end of the experiment the solid phase was freeze-dried and analysed for $\mathrm{P}$ chemical fractions. 
Three replicates of each soil were also destructively sampled after the second, third, fourth, sixth, eight, tenth and final cycle and the soil extracted as described below. The total experiment consisted of approximately 300 vials and each data point represents the mean of a minimum of three replicates.

\section{$5 \quad 2.3$ Laboratory methods}

The analytical methodologies used here are described briefly in Scalenghe et al. (2002) and more fully by Barberis et al. (1996). Total soil P was determined by fusion with $\mathrm{NaOH}$, total soil organic $\mathrm{P}$ was estimated using the ignition method of Legg and Black (1955).

This assumes that the difference between the $\mathrm{HCl}$-extractable $\mathrm{P}$ of a soil sample ignited at $513 \mathrm{~K}$ with that of the original unignited sample can be broadly considered as "organically bounded". Phosphorus forms were fractionated by the method of Olsen and Sommers (1982) which includes a sequential extraction with

1a. $1 \mathrm{M} \mathrm{NaOH}, \mathrm{P}_{\mathrm{NaOH}}$, to remove $\mathrm{P}$ associated to $\mathrm{Fe}$ and $\mathrm{Al}$ (hydr-)oxides

15 1b. citrate bicarbonate, $P C B$, to remove $P$ adsorbed by carbonates during the preceding extraction (the data from these two extractions are presented as the combined value, $\mathrm{P}_{\mathrm{NaOH}-\mathrm{CB}}$ ),

2. Na citrate bicarbonate dithionite, $P_{C B D}$, to remove occluded $P$ within the $\mathrm{Fe}$ and Al oxides, and

$20 \quad 3.1 \mathrm{M} \mathrm{HCl}, \mathrm{P}_{\mathrm{HCl}}$, to remove bound $\mathrm{P}$ to $\mathrm{Ca}$.

Residual $P$ was calculated as the difference between the sum of the three sequential extractions and total $\mathrm{P}$. An estimate of plant available $\mathrm{P}, \mathrm{P}_{\mathrm{Ols}}$, was determined according to Olsen et al. (1954).

Phosphorus in the solutions was determined using either the method of Murphy and 25 Riley (1962) for $\mathrm{P}$ concentrations $>1.6 \mathrm{mmol} \mathrm{m}^{-3}$ (molybdate-reactive $\mathrm{P}-\mathrm{MRP}$ ), or by 9015

the malachite green method of Ohno and Zibilske (1991) as modified by Barberis et al. (1998) for lower concentrations. Iron and Mn were determined by atomic adsorption spectrometry.

\section{Results}

5 Despite the varying pedological and management systems of the soils a generalised pattern of behaviour was clearly evident. This consisted of 4 separate stages with boundaries identified on the basis of changing equilibrating solution $\mathrm{pe}+\mathrm{pH}$ conditions and concentrations of MRP, Mn and Fe.

Changes in solution composition occurred rapidly after submersion, with the most 10 significant increase in $\mathrm{P}$ concentrations occurring between a couple of days and one week. Increasingly reducing conditions were characterised by rising MRP, Mn and Fe concentrations (stages 1-3) until complete reduction was reached after an average of 24 days. Finally, stage 4 (up to 600 days) was characterised by a constantly elevated MRP concentration but greatly reduced $\mathrm{Mn}$ and Fe concentrations indicating a possible 5 shift in the solid phase solubility.

\subsection{Properties of the soils}

The general properties of soils include: $\mathrm{pH}$ ranging from 4.6 to 7.8 and organic carbon from 7 to $39 \mathrm{~g} \mathrm{~kg}^{-1}$. Extractable forms of $\mathrm{Fe}$ and $\mathrm{Al}$ differ widely; the $\mathrm{Fe}_{\mathrm{ox}} / \mathrm{F}_{\mathrm{ed}}$ ratio (an index of the degree of iron crystallinity; Delgado and Torrent, 1997) ranged from 0.07 to 0.77 being $>0.5$ in three soils (G3, D3 and I1).

\subsection{Properties of the equilibrating solution}

During the experiment care was taken to ensure that the soils reached stage 3 (see above and defined by Scalenghe et al., 2002) conditions $(5<\mathrm{pe}+\mathrm{pH}<9)$ by measuring $\mathrm{pe}+\mathrm{pH}$ at the end of each submersion period. 
The pattern of changing MRP concentrations were generally similar for all soils (except I1 and D3) (Fig. 1, left side). Generally, MRP concentrations increased by an order of magnitude compared to initial values, up to the 4th redox pulse (equivalent to 80 days of cumulative reducing conditions). This preliminary period can be equated to

5 the episodic conditions likely to be experienced over timescales of less than a month.

There followed a sharp decline in MRP to concentrations similar or only slightly greater than initial values. Finally, from the 6th redox pulse (i.e. 120 days of reducing conditions) onwards MRP concentrations increased but never reached the large values attained after the 4th pulse. The maximum MRP concentrations measured ranged from

$10 \sim 2$ to $7 \mathrm{~g} \mathrm{P} \mathrm{m}^{-3}$. For all soils the MRP concentrations for any equivalent length of reducing conditions were generally greater under the pulsed (Fig. 1, left side) compared to the continuously reduced conditions (Fig. 1, right side).

Concentrations of $\mathrm{Mn}$ and Fe followed a similar trend and both increased rapidly up to a maximum after the 5th redox pulse. Concentrations subsequently declined but 15 were generally greater than those for the equivalent continuous reducing conditions.

\subsection{Changes in solid phase $P$ forms}

Initially, organic $\mathrm{P}$ for all soil groupings ranged from 13 to $30 \%$ of total $\mathrm{P}$ (Barberis et al., 1996). A common trend displayed by all soils in response to the pulsed redox conditions was a loss of organic $P$ (Table 1). The magnitude of the loss differed between soils but

20 for all soil groups the largest change occurred by the 4th pulse when averaged values were less than half the original organic $\mathrm{P}$ concentration. After subsequent pulses the behaviour differed with an apparent recovery of organic-P concentrations for $C$ and ALT soils compared to a pattern of continuing decline for SA and AOMR soils. The largest decline in organic $\mathrm{P}$ over the full sequence of the experiment ranged from $20 \%$ of total $25 \mathrm{P}$ to $<2 \%$, which occurred for the AOMR group.

The contrasting behaviour of MRP which initially increased compared to a decrease in organic $\mathrm{P}$ resulted in concentrations being comparable after the 4th pulsed cycle (Fig. 2). After a greater number of pulsed redox cycles concentrations started to 9017

diverge, although the range of concentrations was much wider. Further information on the changes in $\mathrm{P}$ forms was provided by the sequential soil extractions (Fig. 3) and provided evidence of substantial transformations occurring within the solid phase. These transformations directly involved from 25 to $60 \%$ of the total soil P. The relative

5 change in individual $P$ forms differed between soils and with number of cycles. The proportion of $\mathrm{P}_{\mathrm{NaOH}+\mathrm{CB}}$ increased steadily with time while residual $\mathrm{P}$ declined. A simple comparison of the $\mathrm{P}_{\mathrm{CBD}}$ and $\mathrm{P}_{\mathrm{HCl}}$ fractions between initial and final would overlook a more complex and dynamic pattern of transformations. In particular, most changes occurred by the 4th pulsed redox cycle. These changes can be summarised as being 10 an increase in $\mathrm{P}_{\mathrm{CBD}}$ and a decrease in $\mathrm{P}_{\mathrm{HCl}}$ to a point that some soils appeared to have temporarily lost all Ca-bound $\mathrm{P}$.

Differences in $\mathrm{P}$ transformation were apparent when the final fractionation of the pulsed experiment (after the 11th cycle) was compared with the continuous reduction (600 days) results (Fig. 4). These could be summarised as being a change from

15 residual $\mathrm{P}$ forms to the more labile and reactive $\mathrm{P}_{\mathrm{NaOH}+\mathrm{CB}}$ extractable form with few significant changes in the $\mathrm{P}_{\mathrm{CBD}}$ or $\mathrm{P}_{\mathrm{HCl}}$ forms.

\subsection{Relationships between $P$ in solution and other soil $P$ test}

Olsen extractable $\mathrm{P}$ was used to represent an extraction method that has been widely adopted for advisory purposes. Changes in concentrations of $\mathrm{P}_{\mathrm{Ols}}$ followed one of three

20 trends, three soils (E1, E2 and E3) declined, while two (I3 and D3) remained relatively unaffected $(<10 \%$ change from the initial value) and the remaining soils all showed an increase over time (data not shown).

The observed trends in MRP concentration in the anoxic solution were compared to $\mathrm{P}_{\text {Ols }}$ contents of the solid phase to explore the possibility that the test method can 25 be used as an indicator of potential $P$ release under reduction. While $\mathrm{P}_{\mathrm{Ols}}$ and MRP were always significantly correlated $\left(r>0.8^{*}\right)$ when all 12 soils were plotted for each sampling occasion, there was no relationship between the trends in either parameter over time for individual soils. The effect of this lack of correlation can be observed in 
the supposed $Q / /$ ratio, where we consider $\mathrm{P}_{\mathrm{Ols}}$ as factor Quantity, and MRP as factor Intensity (Fig. 5).

The significance of these changes in equilibrating solution MRP and $\mathrm{P}_{\mathrm{Ols}}$ are demonstrated in Table 2 where change in concentration $\left(\mathrm{mg} \mathrm{P} \mathrm{kg}^{-1}\right)$ between initial and the

5 2nd pulse have been calculated. The changes observed for MRP were typically greater than those of $\mathrm{P}_{\mathrm{Ols}}$. The maximum change in MRP was measured during the 4th cycle (except for two soils G3 and G6) and ranged between 10 and $24 \mathrm{mg} \mathrm{P} \mathrm{kg}^{-1}$ which is equivalent to 15 and $36 \mathrm{~kg} \mathrm{Pha}^{-1}$ (assuming a value of $1500 \mathrm{tha}^{-1}$ soil to a depth of $10 \mathrm{~cm})$.

\section{Discussion}

Although speculative, it is possible to provide insight into the sequence of events that might be influencing soluble $P$ dynamics under field conditions during periodic flooding and re-oxidation. A particularly important feature will be the availability of nitrate since the sequence of individual redox thresholds theoretically (e.g. Colman et al., 2008;

15 Davidson et al., 2008) follows the order $\mathrm{NO}_{3}-\mathrm{Mn}-\mathrm{Fe}$ towards redox potential of zero $\mathrm{mV}$. The presence or absence of nitrate in soil profile will determine the rate at which Mn starts becoming the key electron acceptor, and therefore influencing P. Seasonal variations in temperature and precipitation will influence nitrate occurrence, typically, in Northern Hemisphere temperate regions it is more likely to be present in the soil profile 20 during Autumn than Spring (e.g. Vos and van der Putten, 2004). This general observation would suggest conditions where the role of $\mathrm{Mn}$ during reduction is more likely during the Spring. Within individual soil peds localised zones of intense nitrate depletion may also develop. It is suggested therefore that there is a strong temporal and spatial component where reduction can directly influence soluble $P$ dynamics. A spe-

25 cific understanding of these interactions might enable a greater opportunity to introduce simple management options (e.g. type and timing of irrigation, presence of labile organic matter, watertable height) that influence $P$ availability through manipulation of the 9019

soil physico-chemical environment, prioritizing the management of individual sources of $\mathrm{P}$ at the catchment scale (Edwards and Withers, 2007; Smolders et al., 2010).

\subsection{Significance and context of repeated redox cycles}

The repeated sequence of redox conditions used here were assumed to simulate what 5 might be expected over the autumn-spring period in the Northern Hemisphere. A change in all soils was measurable within the 4th cycle (a period of time roughly comparable to the findings by Contin et al., 2007 either Grunth et al., 2008 or Velázquez et al., 2004) and perhaps the most interesting from an agronomic and also environmental perspective is the substantial increase in MRP that was readily measurable in the equilibrating solution.

Considering the wide variety of properties of the soils included in this study a multiplicity of mechanisms are likely to be involved in $\mathrm{P}$ release (Delgado and Torrent, 2000; Scalenghe et al., 2007; Schärer et al., 2009). The most direct and obvious process is the reduction, and subsequent oxidation, of $\mathrm{Mn}$ and Fe oxides which would release any

15 adsorbed or occluded P. Alternate reducing and oxidizing conditions would promote the solubilisation of these oxides and their subsequent precipitation as amorphous phases (e.g. Contin et al., 2007) which are in turn more prone to act as electron acceptors pulse by pulse. In addition, their solubilisation would expose new surfaces to reduction at every cycle. Iron transformations can have a profound influence on soil P biogeo-

20 chemistry (Brand-Klibanski et al., 2007; Schärer et al., 2009; Thompson et al., 2006; Trolard and Bourrié, 2008). For example, upon reoxidation, ferrous Fe could neoform Fe-oxides that can scavenge the solution, eliminating organic acids, metal cations and oxyanions. Current understanding suggests that oxidative supersaturation of organicrich soil solutions will favour initially the formation of aqueous organic-Fe complexes

25 and short-range ordered oxides (SRO), rather than well-ordered Fe-oxides. Subsequent onset of reducing conditions can be expected to preferentially dissolve SRO Fe-oxides, but also more crystalline varieties (e.g. goethite) to some smaller degree (Bonneville et al., 2004; Roden, 2004). Thus, repeated redox cycles are suggested to 
promote the accumulation of $\mathrm{SRO} F e-o x i d e s$ as they are the primary predicted products formed during the oxidizing stages.

There was some evidence that part of the organically associated $\mathrm{P}$ may have contributed to the increased MRP as organic molecules are being used as electron donors.

5 The length of reducing conditions (Brand-Klibanski et al., 2007) the occurrence (Pant and Reddy, 2001; Quintero et al., 2007) and type of organic matter (Nagarajah et al., 1989) each effect the rate of reduction and consequently soil P-adsorption properties. As the reduction process progressed the behaviour of $\mathrm{Mn}, \mathrm{Fe}$ and $\mathrm{P}$ became less interdependent and while a new Fe phase was precipitated this was not accompanied by

10 adsorption of $P$. Under field conditions there is evidence that drainage of previously flooded soil and the development of oxidising conditions result in a simultaneous decrease in soluble $\mathrm{P}$ and $\mathrm{Fe}$ and an increase of organically bound $\mathrm{P}$ (e.g. Shenker et al., 2005). In all our soils, the consequence of alternating reducing and oxidising conditions, is an initial decrease in organic $\mathrm{P}$ to half the original concentrations followed by

15 a later recovery. It appears that low molecular weight organic matter is oxidized at first, releasing $\mathrm{P}$; the development of anaerobic microorganisms would metabolize the $\mathrm{P}$ in solution and convert it to organic $\mathrm{P}$ again (Miller et al., 2001; Mukherjee et al., 2009; Unger et al., 2009).

Some $\mathrm{P}$ release could also be due to the dissolution of phosphates in calcareous soils, whose $\mathrm{pH}$ decreases under reducing conditions. Changes in $\mathrm{pH}$ would also bring along changes in the surface charge of mineral and organic surfaces and would therefore alter the adsorption/desorption equilibria (e.g. Darke and Walbridge, 2000).

One possible explanation of the elevated ionic concentration of the equilibrating solution may also be the lack of initial synchronisation of change between $\mathrm{pH}$ and $\mathrm{pe}$ (as proposed by Olila and Reddy, 1995; Scalenghe et al., 2002). The lack of synchronisation would result in (i) rapid sorption at low ionic concentration, which is unaffected by $\mathrm{pH}$; (ii) slow sorption at moderate ionic concentration which decreases with increasing $\mathrm{pH}$ and (iii) sorption at supersaturated conditions which increases with increasing $\mathrm{pH}$.

9021

Concentrations of MRP in the equilibrating solution are therefore controlled by the amount of $\mathrm{P}$ released on reduction of the citrate/ascorbate-extractable Fe forms (e.g. de Mello et al., 1998). In these cases, the precipitation of Ca-P minerals could be seen as the key mechanism of control; an increased P-retention capacity upon reoxidation 5 could oversaturate with respect to hydroxyapatite and occasionally $\beta-\mathrm{Ca}_{3}\left(\mathrm{PO}_{4}\right)_{2}$, indicating that in spite of the large $\mathrm{Ca}$ concentration, the rate of $\mathrm{Ca}-\mathrm{P}$ precipitation was insufficient to maintain the saturation status of the Ca-P system (e.g. Shenker et al., 2005; Scalenghe et al., 2007).

Beyond the 4th cycle the MRP fraction declines rapidly suggesting a significant trans10 formation in less soluble $\mathrm{P}$ forms, most probably because the system approaches a biological and chemical equilibrium, as was the case of the continuous reduction experiment (Scalenghe et al., 2002). An overall comparison of the latter with the present results clearly indicates that fluctuating oxic-anoxic condition can have serious consequences in terms of $\mathrm{P}$ management.

15 However, the lack of any clear relationship with a standard soil test (here Olsen) is potentially important and because the change in MRP concentrations was in many cases greater than $\mathrm{P}_{\mathrm{Ols}}$ (even for the calcareous soils) this indicates a general inability of this test $\mathrm{P}$ extraction to predict short-term physico-chemical changes in $\mathrm{P}$ solubility. This is in line with what reported by Mukherjee et al. (2009) who reported a poor 20 correlation between different soil P tests (STP) and water extractable P in wetland soils.

\subsection{Changes in solid phase $P$ forms}

The changes in $\mathrm{P}$ forms confirm that pulsed reduction can bring be associated with more complex patterns of $\mathrm{P}$ transformation with respect to continuous anoxia. The fact that up to $60 \%$ of the total soil $P$ was demonstrated to change its sensitivity for a 25 particular extractant suggests that these operationally defined $\mathrm{P}$ forms can experience substantial transformations.

Despite the wide range in relative concentrations of the various $P$ forms, generally, the overall pattern of response was common for all soils and indicate that soil $\mathrm{P}$ 
tends to become more labile with succeeding pulses (e.g. Ajmone-Marsan et al., 2006). Concentrations of MRP initially increased while those of organic P decreased and concentrations became comparable after 80 days of pulsed redox conditions (e.g. Fig. 4). After longer periods of pulsed reduction these two concentrations started to diverge, al5 though the range of concentrations was much wider. The $P$ forms determined after the final reducing period showed an apparently similar distribution when comparing pulsed and continuous reduction (Fig. 5). When considered together, $P$ forms associated with the amorphous phases of all soils, as indicated by $\mathrm{P}_{\mathrm{NaOH}-\mathrm{CB}}$ extraction increase considerably after the pulsed reducing conditions (Fig. 5). After the same period of time

10 under continuous reducing conditions this phenomenon was not observed (Scalenghe et al., 2002). Scalenghe et al. (2002) studying the continuous flooding of these soils suggested that despite the large concentrations of $\mathrm{Fe}$ and $\mathrm{P}$, in particular during the first month of reduction (i.e. Stage 3), it is unlikely that any co-precipitation would have occurred. This is further substantiated by the contrasting trends observed between $\mathrm{Mn}$ 15 and Fe with MRP during the long-term period of reduction (Stage 4). Siderite could have coexisted with other iron minerals, but in that situation $\mathrm{CO}_{2}$ was not the controlling factor in iron precipitation as magnetite would had prevailed. They hypothesized precipitation of rhodochrosite, however, under those redox conditions $\mathrm{Mn}$ (II) solubility was governed by either $\mathrm{MnCO}_{3}$ or manganite $(\mathrm{MnOOH})$. In that case, $\mathrm{P}$ did not control 20 the precipitation of $\mathrm{Mn}(\mathrm{II})$.

Although not quantified one possible explanation might involve microorganisms and their ability to affect biogeochemical processes, this can be underestimated as $\mathrm{Mn}$ (III) is both an electron acceptor or donor. Trouwborst et al. (2006) demonstrated that oneelectron transfer reactions are more important for $\mathrm{Mn}$ biogeochemistry than previously 25 thought. In fact, as the $d_{z^{2}}$ and $d_{x^{2}-y^{2}}$ orbitals that can accept electrons in $\mathrm{MnO}_{2}$ or donate electrons from $\mathrm{Mn}(\mathrm{II})$ are spatially distinct, reduction of $\mathrm{MnO}_{2}$ or oxidation of $\mathrm{Mn}$ (II) should lead to $\mathrm{Mn}$ (III) species via one-electron transfer processes (Luther, 2005). Mn(III) will also compete with Fe(III) for these ligands (Parker et al., 2004). In our case, under both pulsed and continuous reducing conditions, despite the large

9023

concentrations of $\mathrm{Fe}$ and $\mathrm{P}$, it is unlikely that any co-precipitation would have occurred. In the case of manganese, under our experimental redox conditions MINTEQ integrated with Lindsay's revised database (Gustafsson, 2010) estimate the possibility of oversaturation in respect to $\mathrm{MnHPO}_{4}$ after 80 days of pulsed reducing conditions for all 5 the soils (data not shown).

\section{Conclusions}

The cycles of reduction-oxidation highlighted the potential that might exist for the management of (bio)available P, perhaps through short-term manipulations of a soils' physico-chemical properties. The ability to manage (bio)available $\mathrm{P}$ over short time 10 periods may offer advantages from an agronomical point of view but also possibly in an environmental context.

A large proportion (up to two thirds) of total soil $P$ is susceptible to a change in extractable form during a sequence of pulsed redox conditions. Changes in the organic and $\mathrm{Ca}$ associated $\mathrm{P}$ fractions are especially apparent. A distinct division over time

15 occurred, with an initial period upto 4 pulsed cycles (equivalent to 80 days cumulative reducing conditions) characterised by an increased concentration of MRP, Mn and Fe in the equilibrating solution. From the 5th pulsed cycle, concentrations of MRP, Mn and Fe started to decline. The quantity of MRP released was equivalent to between 15$36 \mathrm{~kg} \mathrm{P}$ per ha and showed no relationship with Olsen extractable P for individual soils.

20 This implies a lack of sensitivity of the Olsen method to the $P$ dynamics that occur in response to reduction. Under reducing conditions consumption of nitrate and dissolution of manganic and ferric hydroxides and release of adsorbed $P$ represents one important source (e.g. Scalenghe et al., 2002; Shenker et al., 2005). This phenomena is magnified by alternating short periods of oxidation within a general condition of anoxia.

25 The rapid and substantial change in MRP measured in response to waterlogging suggests that Olsen extractable $P$ does not extract the $P$ that is immediately susceptible to reduction. A greater understanding of the redox sensitive soil $\mathrm{P}$ component might 
help to provide an opportunity for greater controlled released through manipulation of soil physico-chemical conditions.

Acknowledgements. This work was initially funded by the European Community (AIR3 CT920303).

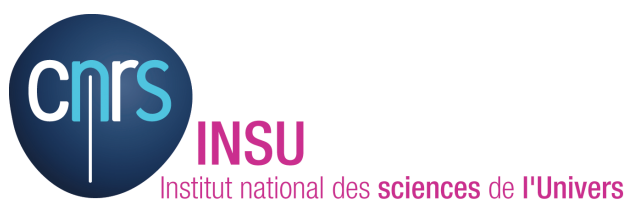

The publication of this article is financed by CNRS-INSU.

\section{References}

Ajmone Marsan, F., Côté, D., and Simard, R. R.: Phosphorus transformations under reduction in long-term manured soils, Plant Soil, 282, 239-250, 2006.

Ascar, L., Ahumada, I., and Richter, P.: Influence of redox potential (Eh) on the availability of arsenic species in soils and soils amended with biosolid, Chemosphere, 72, 1548-1552, 2008.

Banach, A. M., Banach, K., Peters, R. C. J. H., Jansen, R. H. M., Visser, E. J. W., Stępniewska,

15 Z., Roelofs, J. G. M., and Lamers, L. P. M.: Effects of long-term flooding on biogeochemistry and vegetation development in floodplains; a mesocosm experiment to study interacting effects of land use and water quality, Biogeosciences, 6, 1325-1339, doi:10.5194/bg-6-13252009, 2009.

Barberis, E., Ajmone Marsan, F., Scalenghe, R., Lammers, A., Schwertmann, U., Edwards, A. C., Maguire, R., Wilson, M. J., Delgado, A., and Torrent, J.: European soils overfertilized with phosphorus: Part 1. Basic properties, Fert. Res., 45, 199-207, 1996.

Barberis, E., Ajmone Marsan, F., and Arduino, E.: Determination of phosphate in solution at different ionic composition using malachite green, Comm. Soil Sci. Plant Anal., 29, 1167$1177,1998$.

Bonneville, S., Van Cappellen, P., and Behrends, T.: Microbial reduction of iron(III) oxyhydroxides: Effects of mineral solubility and availability, Chem. Geol., 212, 255-268, 2004.

Brand-Klibanski, S., Litaor, M. I., and Shenker, M.: Overestimation of phosphorus adsorption capacity in reduced soils: An artifact of typical batch adsorption experiments, Soil Sci. Soc. Am. J., 71, 1128-1136. 2007.

Christensen, J. H., Hewitson, B., Busuioc, A., Chen, A., Gao, X., Held, I., Jones, R., Kolli, R. K., Kwon, W.-T., Laprise, R., Magaña Rueda, V., Mearns, L., Menéndez, C. G., Räisänen, J., Rinke, A., Sarr, A., and Whetton, P.: Regional climate projection, in: Contribution of Working Group I to the Fourth Assessment Report of the Intergovernmental Panel on Climate Change, edited by: Solomon, S., Qin, D., Manning, M., Chen, Z., Marquis, M., Averyt, K. B., Tignor, M., and Miller, H. L., available at: http://www.ipcc.ch/pdf/assessment-report/ar4/wg1/ ar4-wg1-chapter11.pdf, last access: December 2010, 2007.

Colman, B. P., Fierer, N., and Schimel, J. P.: Abiotic nitrate incorporation, anaerobic microsites, and the ferrous wheel, Biogeochemistry, 91, 223-227, 2008.

Contin, M., Mondini, C., Leita, L., and De Nobili, M.: Enhanced soil toxic metal fixation in iron (hydr)oxides by redox cycles, Geoderma, 140, 164-175, 2007.

Darke, A. K. and Walbridge, M. R.: Al and Fe biogeochemistry in a floodplain forest: Implications for $P$ retention, Biogeochemistry, 51, 1-32, 2000.

Davidson, E. A., Chorover, J., and Dail, D. B.: Iron interference in the quantification of nitrate in soil extracts and its effect on hypothesized abiotic immobilization of nitrate, Biogeochemistry, 90, 65-73, 2008.

Deacon, L. J., Grinev, D. V., Crawford, J. W., Harris, J., Ritz, K., and Young, I. M.: Simultaneous preservation of soil structural properties and phospholipids profiles: A comparison of three drying techniques, Pedosphere, 18, 284-287, 2008.

25 Delgado, A. and Torrent, J.: Phosphate-rich soils in the European Union: Estimating total plantavailable phosphorus, Eur. J. Agron., 6, 205-214, 1997.

Delgado, A. and Torrent, J.: Phosphorus forms and desorption patterns in heavily fertilized calcareous and limed acid soils, Soil Sci. Soc. Am. J., 64, 2031-2037, 2000.

de Mello, J. W. V., Barron, V., and Torrent, J.: Phosphorus and iron mobilization in flooded soils from Brazil, Soil Sci., 163, 122-132, 1998.

Edwards, A. C. and Withers, P. J. A.: Linking phosphorus sources to impacts in different types of water body, Soil Use Manage., 23, 133-143, 2007.

Gao, S., Ryu, J., Tanji, K. K., and Herbel, M. J.: Arsenic speciation and accumulation in 
evapoconcentrating waters of agricultural evaporation basins, Chemosphere, 67, 862-871, 2007.

Gustafsson, J. P.: Visual MINTEQ 3.0. beta version: http://www.lwr.kth.se/English/ OurSoftware/vminteq/\#download, last access: December 2010.

5 Gordon, H., Haygarth, P. M., and Bardgett, R. D.: Drying and rewetting effects on soil microbial community composition and nutrient leaching, Soil Biol. Biochem., 40, 302-311, 2008.

Grunth, N. L., Askaer, L., and Elberling, B.: Oxygen depletion and phosphorus release following flooding of a cultivated wetland area in Denmark, Geogr. Tidsskr., 108, 17-25, 2008.

Hernandez, J. and Meurer, E. J.: Phosphorus availability in six Uruguayan soils affected by temporal variation of oxidising-reducing conditions, Rev. Bras. Cienc. Solo, 24, 19-26, 2000.

IUSS Working Group WRB: World Reference Base for Soil Resources 2006, 2nd edn., World Soil Resources Reports No. 103. FAO, Rome, IT EU, 2006.

James, B. R. and Bartlett, R. J.: Redox phenomena, in: Handbook of Soil Science, edited by: Sumner, M. E., B-169-B-194, CRC Press, Boca Raton, FL USA, 2000.

15 Luther III, G. W.: Manganese(II) oxidation and Mn(IV) reduction in the environment - two oneelectron transfer steps versus a single two-electron step, Geomicrobiol. J., 22, 195-203, 2005.

Meehl, G. A., Stocker, T. F., Collins, W. D., Friedlingstein, P., Gaye, A. T., Gregory, J. M., Kitoh, A., Knutti, R., Murphy, J. M., Noda, A., Raper, S. C. B., Watterson, I. G., Weaver, A. J., and

20 Zhao, Z.-C.: Global climate projections, in: Contribution of Working Group I to the Fourth Assessment Report of the Intergovernmental Panel on Climate Change, edited by: Solomon, S., Qin, D., Manning, M., Chen, Z., Marquis, M., Averyt, K. B., Tignor, M., and Miller, H. L., available at: http://www.ipcc.ch/pdf/assessment-report/ar4/wg1/ar4-wg1-chapter10.pdf, last access: December 2010, 2007.

25 Miller, A. J., Schuur, E. A. G., and Chadwick, O. A.: Redox control of phosphorus pools in Hawaiian montane forest soils, Geoderma, 102, 219-237, 2001.

Mukherjee, A., Nair, V. D., Clark, M. W., and Reddy, K. R.: Development of indices to predict phosphorus release from wetland soils, J. Environ. Qual., 38, 878-886, 2009.

Nagarajah, S., Neue, N. V., and Alberto, M. C. R.: Effect of Sesbana, Azolla, and rice straw incorporation on the kinetics of $\mathrm{NH}_{4}, \mathrm{~K}, \mathrm{Fe}, \mathrm{Mn}, \mathrm{Zn}$ and $\mathrm{P}$ in some flooded rice soils, Plant Soil, 116, 37-48, 1989.

Niedermeier, A. and Robinson, J. S.: Hydrological controls on soil redox dynamics in a peatbased, restored wetland, Geoderma, 137, 318-326, 2007.

9027

Olsen, S. R., Cole, C. V., Watanabe, F. S., and Dean, L. A.: Estimation of available phosphorus in soils by extraction with sodium bicarbonate, USDA circular 939 US Gov. Print. Office, Washington, DC USA, 1954.

Pant, H. K. and Reddy, K. R.: Phosphorus sorption characteristics of estuarine sediments under different redox conditions, J. Environ. Qual., 30, 1474-1480, 2001.

Pant, H. K., Nair, V. D., Reddy, K. R., Graetz, D. A., and Villapando, R. R.: Influence of flooding on phosphorus mobility in manure-impacted soil, J. Environ. Qual., 31, 1399-1405, 2002.

Parker, D. L., Sposito, G., and Tebo, B. M.: Manganese (III) binding to a pyoverdine siderophore produced by a manganese (II)-oxidizing bacterium, Geochim. Cosmochim. Ac., 68, 48094820, 2004.

Phillips, I. R.: Phosphorus availability and sorption under alternating waterlogged and drying conditions, Comm. Soil Sci. Plant Anal., 29, 3045-3059, 1998.

Phillips, I. R. and Greenway, M.: Changes in water-soluble and exchangeable ions, cation exchange capacity, and phosphorus (Max) in soils under alternating waterlogged and drying conditions, Comm. Soil Sci. Plant Anal., 29, 51-65, 1998.

Ponnamperuma, F. N.: The chemistry of submerged soils, Adv. Agron., 24, 29-96, 1972.

Quintero, C. E., Gutiérrez-Boem, F. H., Romina, M. B., and Boschetti, N. G.: Effects of soil flooding on $\mathrm{P}$ transformations in soils of the Mesopotamia region, Argentina, J. Plant Nutr. Soil Sc., 170, 500-505, 2007.

20 Rinklebe, J., Franke, C., and Neue, H. U.: Aggregation of floodplain soils based on classification principles to predict concentrations of nutrients and pollutants, Geoderma, 141, 210-223, 2007.

Reddy, K. R., Wetzel, R. G., and Kadlec, R.: Biogeochemistry of phosphorus in wetlands, in: Phosphorus: Agriculture and the Environment, edited by: Sims, J. T. and Sharpley, A. N., Agronomy Monograph 46, SSSA, Madison, WI USA, 263-316, 2005.

Roden, E. E.: Analysis of long-term bacterial vs chemical Fe(III) oxide reduction kinetics, Geochim. Cosmochim. Ac., 68, 3205-3216, 2004.

Scalenghe, R., Edwards, A. C., Ajmone Marsan, F., and Barberis, E.: The effect of reducing conditions on $\mathrm{P}$ solubility for a diverse range of European agricultural soils, Eur. J. Soil Sci., 53, 439-448, 2002.

Scalenghe, R., Edwards, A. C., and Barberis, E.: Phosphorus loss in overfertilized soils: the selective $P$ partitioning and redistribution between particle size separates, Eur. J. Agron., 27, 72-80, 2007. 
Schärer, M., De Grave, E., Semalulu, O., Sinaj, S., Vandenberghe, R. E., and Frossard, E.: Effect of redox conditions on phosphate exchangeability and iron forms in a soil amended with ferrous iron, Eur. J. Soil Sci., 60, 386-397, 2009.

Shenker, M., Seitelbach, S., Brand, S., Haim, A., and Litaor, M. I.: Redox reactions and phos5 phorus release in re-flooded soils of an altered wetland, Eur. J. Soil Sci., 56, 515-525, 2005.

Simojoki, A., Fazekas-Becker, O., and Horn, R.: Macro- and microscale gaseous diffusion in a Stagnic Luvisol as affected by compaction and reduced tillage, Agr. Food Sci., 17, 252-264, 2008.

Smolders, A. J. P., Lucassen, E. C. H. E. T., Bobbink, R., Roelofs, J. G. M., and Lamers, L. P. M.: How nitrate leaching from agricultural lands provokes phosphate eutrophication in groundwater fed wetlands: The sulphur bridge, Biogeochemistry, 98, 1-7, 2010.

Soil Survey Staff: Keys to Soil Taxonomy, 11th edn., USDA, Natural Resources Conservation Service, US Gov. Print. Office, Washington, DC USA, 2010.

Suplee, M. W. and Cotner, J. B.: An evaluation of the importance of sulfate reduction and

15 temperature to $P$ fluxes from aerobic-surfaced, lacustrine sediments, Biogeochemistry, 61, 199-228, 2002.

Thompson, A., Chadwick, O. A., Rancourt, D. G., and Chorover, J.: Iron-oxide crystallinity increases during soil redox oscillations, Geochim. Cosmochim. Ac., 70, 1710-1727, 2006.

Trolard, F. and Bourrié, G.: Geochemistry of green rusts and fougerite: A reevaluation of the Fe cycle in soils, Adv. Agron., 99, 227-288, 2008.

Trouwborst, R. E., Clement, B. G., Tebo, B. M., Glazer, B. T., and Luther III, G. W.: Soluble $\mathrm{Mn}(\mathrm{III})$ in suboxic zones, Science, 313, 1955-1957, 2006.

Unger, I. M., Kennedy, A. C., and Muzika, R. M.: Flooding effects on soil microbial communities, Appl. Soil Ecol., 42, 1-8, 2009.

25 Velázquez, M., del Campillo, M. C., and Torrent, J.: Temporary flooding increases iron phytoavailability in calcareous Vertisols and Inceptisols, Plant Soil, 266, 195-203, 2004.

Vos, J. and van der Putten, P. E. L.: Nutrient cycling in a cropping system with potato, spring wheat, sugar beet, oats and nitrogen catch crops. II. Effect of catch crops on nitrate leaching in autumn and winter, Nutr. Cycl. Agroecosys., 70, 23-31, 2004.

30 Wegener, G. and Boetius, A.: An experimental study on short-term changes in the anaerobic oxidation of methane in response to varying methane and sulfate fluxes, Biogeosciences, 6 , 867-876, doi:10.5194/bg-6-867-2009, 2009.

Williams, E. G.: Influences of parent material and drainage conditions on soil phosphorus 9029

relationships, Agrochimica, 4, 279-309, 1959.

Zhou, X., Jianping, D., Jianbao, G., and Ziniu, Y.: Activity-loss characteristics of spores of Bacillus thuringiensis during spray drying, Food Bioprod. Process., 86, 37-42, 2008.

Zhang, J., Gilbert, D., Gooday, A. J., Levin, L., Naqvi, S. W. A., Middelburg, J. J., Scranton, $5 \quad$ M., Ekau, W., Peña, A., Dewitte, B., Oguz, T., Monteiro, P. M. S., Urban, E., Rabalais, N. N., Ittekkot, V., Kemp, W. M., Ulloa, O., Elmgren, R., Escobar-Briones, E., and Van der Plas, A. K.: Natural and human-induced hypoxia and consequences for coastal areas: synthesis and future development, Biogeosciences, 7, 1443-1467, doi:10.5194/bg-7-1443-2010, 2010. 
Table 1. Changes in soil organic $P$ measured at intervals over the 11 redox pulsed cycles. Results are expressed as the percentage of total $\mathrm{P}$ and averaged according to soil groups ${ }^{1}$.

\begin{tabular}{lrrrrrrrr}
\hline Pulse $^{2}$ & $0^{4}$ & 2 & 3 & 4 & 6 & 8 & 10 & 11 \\
Days $^{3}$ & Oxic $^{4}$ & 40 & 60 & 80 & 120 & 160 & 200 & 220 \\
\hline $\mathrm{C}^{1}$ & 30.2 & 29.7 & 26.7 & 12.4 & 9.9 & 15.3 & 25.1 & 27.5 \\
$\mathrm{SA}^{1}$ & 13.4 & 15.3 & 14.0 & 5.8 & 5.0 & 6.9 & 4.8 & 4.3 \\
$\mathrm{AOMR}^{1}$ & 20.0 & 21.8 & 21.4 & 7.1 & 6.4 & 3.5 & 2.3 & 1.8 \\
$\mathrm{ALT}^{1}$ & 17.0 & 15.8 & 6.2 & 3.7 & 3.1 & 6.1 & 6.3 & 9.3 \\
\hline
\end{tabular}

${ }^{1} \mathrm{C}$ calcareous, SA slightly acid, AOMR acid organic matter rich, ALT acid light-textured.

2 Individual cycle involves a reduction period of 20 days $(298 \mathrm{~K})$ followed by a period $(24 \mathrm{~h})$ of oxidized conditions (preflushed with $\mathrm{O}_{2}$ ) and open air at $313 \mathrm{~K}$. At the end of the oxidation period soil was freeze dried $(24 \mathrm{~h})$.

${ }^{3}$ Total number of days of pulsed reduced conditions.

${ }^{4}$ Initial oxidising conditions.

Table 2. A comparison of the change in Olsen $P$ and MRP in the equilibrating solution between the initial and 2nd redox pulse. The maximum concentration of MRP measured in the equilibrating solution is also shown and occurred after the 4th pulse (except for two soils shown in bold where it was the 3 rd pulse). All units are as $\mathrm{mg} \mathrm{P} \mathrm{kg}^{-1}$.

\begin{tabular}{|c|c|c|c|c|}
\hline \multicolumn{2}{|c|}{ Groupings } & Olsen & MRP & $\begin{array}{l}\text { Maximum MRP } \\
\text { concentration }\end{array}$ \\
\hline \multirow{3}{*}{ C } & E1 & 3.0 & 8.4 & 18.3 \\
\hline & E2 & -3.5 & 7.9 & 13.9 \\
\hline & 13 & 16.4 & 6.2 & 13.1 \\
\hline \multirow{4}{*}{ SA } & D1 & -2.0 & 14.2 & 22.2 \\
\hline & D2 & 5.4 & 13.0 & 24.5 \\
\hline & E3 & -5.1 & 4.5 & 10.4 \\
\hline & 12 & -1.1 & 7.1 & 17.0 \\
\hline \multirow{3}{*}{ AOMR } & G3 & 6.4 & 8.9 & 15.3 \\
\hline & G6 & -3.1 & 12.8 & 21.2 \\
\hline & G9 & 3.8 & 4.6 & 10.1 \\
\hline \multirow{2}{*}{ ALT } & I1 & -6.3 & 16.2 & 24.1 \\
\hline & D3 & 4.2 & 6.3 & 21.0 \\
\hline
\end{tabular}




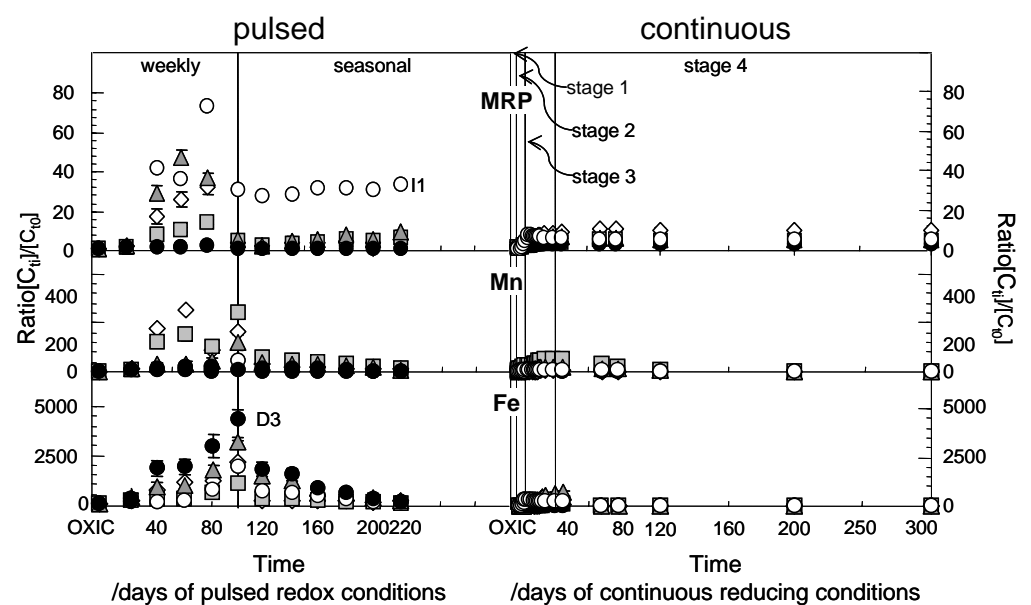

Fig. 1. Changes in solution concentrations of molybdate-reactive $\mathrm{P}, \mathrm{Mn}$ and Fe collected over 220 days of pulsed reducing conditions compared to 300 days of continuous reducing conditions (data from Scalenghe et al., 2002). Results are expressed as a ratio of the respective initial concentrations and averaged for the soil groups: $(\diamond)$ calcareous $(C)$, ( $\square$ ) slightly acid $(\mathrm{SA}),(\triangle)$ acid OM rich (AOMR) soil, $(\bullet)$ acidic light-textured soil (D3) and (o) is the paddy soil (I1) (average \pm standard error of the mean). All values have been divided by 100 for the paddy soil (I1). On the left hand side, the dotted line is indicative of a boundary between medium (weekly/seasonal) and longer-term (seasonal/annual) exposure to pulsed redox conditions. On the right hand side individual stages are also indicated. Where stage 1 is characterized by an oxygen-rich environment $(\mathrm{pe}+\mathrm{pH}>12)$; stage $2(9<\mathrm{pe}+\mathrm{pH}<12)$ represents the approximate range for the theoretical complete oxygen depletion and the start of $\mathrm{Mn}$ reduction; stage 3 $(5<\mathrm{pe}+\mathrm{pH}<9)$ represents the interval for the persistence of nitrate; and stage $4(\mathrm{pe}+\mathrm{pH}<5)$ represents the steady reducing environment and under continuous reducing conditions (from Scalenghe et al., 2002). These stages are equivallent to an approximate timescale of daily, weekly, monthly and annual exposure to redution under field condition, respectively.

9033

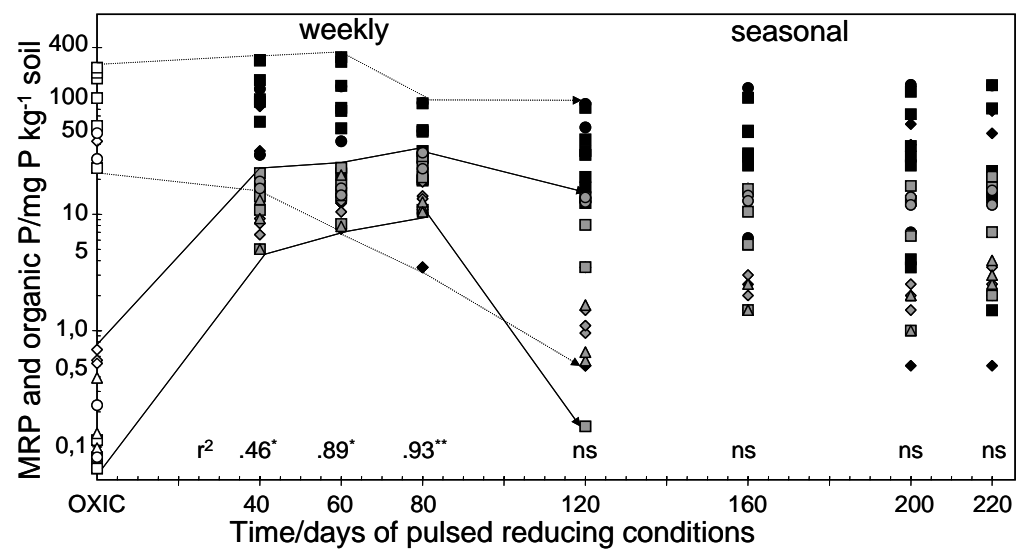

Fig. 2. Changes in MRP (grey symbols, solid lined) and organic $P$ (filled symbols, dotted lines) over 220 days of pulsed redox conditions. Symbols are sorted by soil groupings where: $(\diamond)$ calcareous $(C),(\square)$ slightly acid (SA), $(\triangle)$ acid OM rich (AOMR) soil, and (०) acidic lighttextured soils. Open symbols indicate the initial conditions of the soils. Data are expressed as means. Standard error of the mean are not shown (always $<10 \%$ ) and the lines represent the concentration range of the twelve soils. 


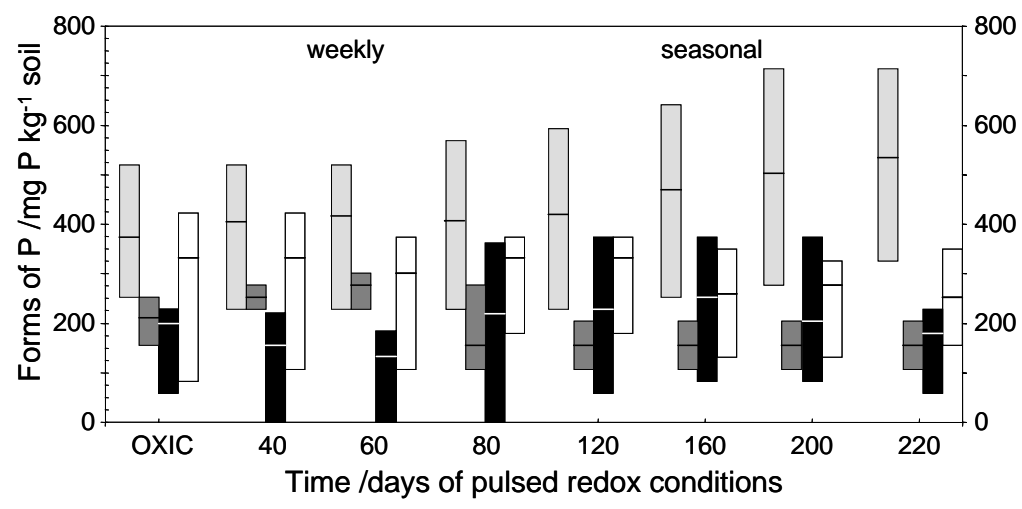

Fig. 3. $P$ form changes through 220 days of pulsed redox conditions. Boxes are interquartiles of the forms of $\mathrm{P}$ over all the 12 soils, where pale grey are $\mathrm{P}_{\mathrm{NaOH}+\mathrm{CB}}$, grey are $\mathrm{P}_{\mathrm{CBD}}$, filled boxes $\mathrm{P}_{\mathrm{HCl}}$ and open boxes show residual $\mathrm{P}$. Lines indicate medians.

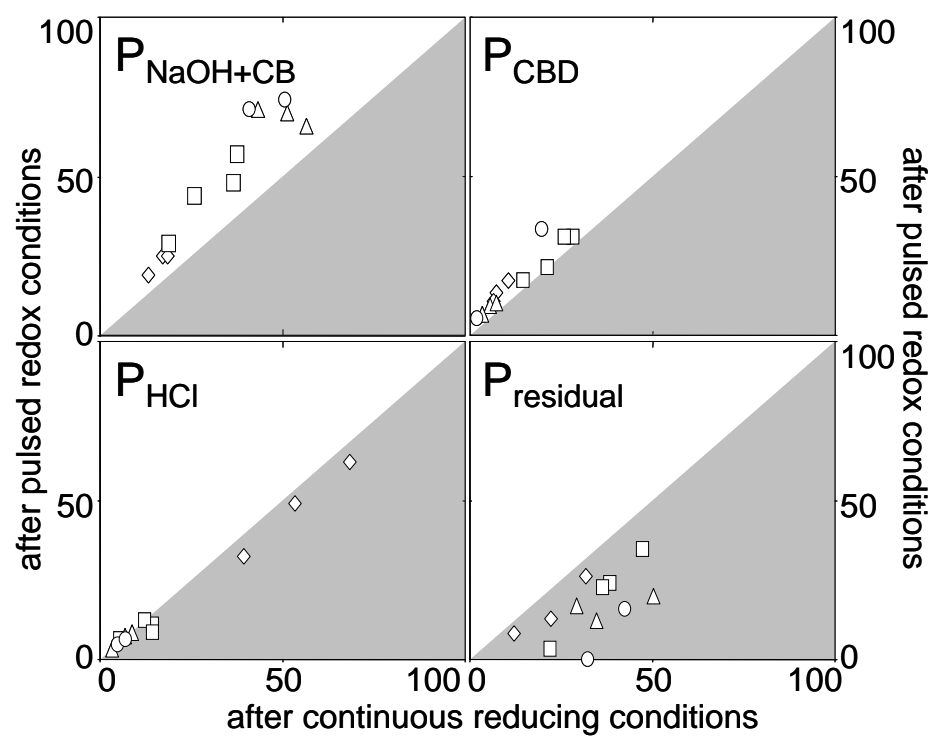

Fig. 4. Forms of $P$ (sequential extraction) collected after being exposed to continuous reducing conditions (stage 4, 600 days) or pulsed redox conditions (seasonal exposure, 220 days). Results are expressed as a percent of the total phosphorus by soil groupings: $(\diamond)$ calcareous $(C)$, $(\square)$ slightly acid (SA), $(\triangle)$ acid OM rich (AOMR) soil, (o) acidic light-textured soils (ALT). Initial concentrations are shown elsewhere (Table 4, Scalenghe et al., 2002). Standard errors of the means are not shown (always $<10 \%$ ). 


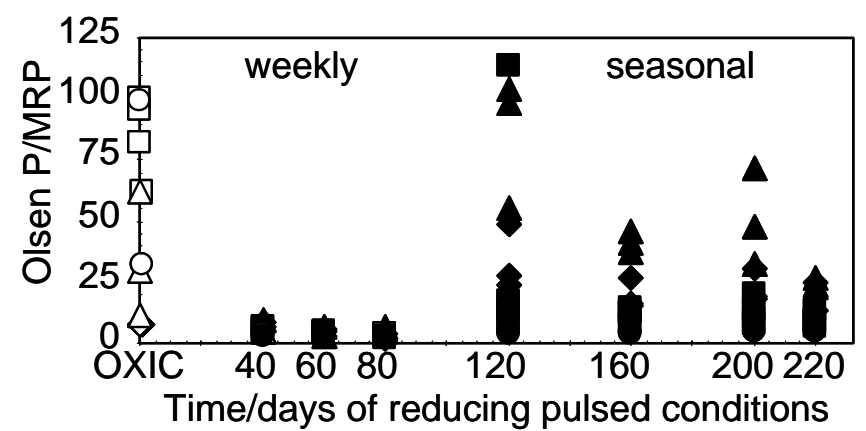

Fig. 5. Changes in $Q / /$ expressed as Olsen extractable phosphorus over MRP collected during a period of pulsed redox conditions. Symbols indicate soil groupings: $(a)(\diamond)$ calcareous $(C)$, (b) ( $\square$ ) slightly acid (SA), (c) $(\triangle)$ acid OM rich (AOMR) soil, and (d) (o) acidic light-textured soils. Open symbols indicate the initial $Q / /$ of the soils divided by 10 . Data are expressed as averaged ratios. Standard error of the mean are not shown (always $<6 \%$ ). 